\title{
OSTEOMETRIC STUDY OF PROXIMAL FEMUR
}

Sobana $\mathrm{M}^{1}$, Nedunchezhiyan $\mathrm{S} * 2$.

${ }^{*_{1}}$ Associate Professor of Anatomy, Madurai Medical College, Madurai, Tamilnadu, India.

${ }^{2}$ Assistant Professor of Anatomy, K.A.P.V.Govt Medical College,Trichy, Tamilnadu, India.

\section{ABSTRACT}

Background: The constitutional built and physique of Indians is entirely different from the western population due to the variation in the genetic makeup and lifestyle. But the prosthesis for proximal femur used in India is manufactured by the western countries whose morphometry does not fit our people leading to complications. Hence, this study is to provide the morphometric data of proximal femur for Indian population and to clear the drawbacks in the information about proximal femur in our people and customize the implant design to suit the Indian people and thereby reduce the complications.

Materials and Methods: The study material consisted of 60 dry femora obtained from the Institute of Anatomy and the parameters studied according to standard anthropometrical methods with appropriate instruments.

Results: In the present study, the average length of the femur was $41.4 \mathrm{~cm}$, diameter of head was $4.17 \mathrm{~cm}$, anterior neck length being $3.42 \mathrm{~cm}$, Neck- shaft angle was $129.9^{\circ}$ and the inter-trochanteric distance $6.13 \mathrm{~cm}$.

Conclusion: This study showed that our values were comparatively smaller than the western people and varied with regional ethnicity. This study will encourage our biomechanical engineers to bring in a revolution in the designing and manufacturing of implants with correct morphometric data to befit our Indian population and lead to improved surgical outcome with minimal surgical complications.

KEY WORDS: Proximal femur, Neck shaft angle, Inter-trochanteric distance, Anterior neck length.

Address for Correspondence: Dr.S.Nedunchezhiyan, Assistant Professor of Anatomy, KAPV Government Medical College, Collector office road, Trichy-620001, Tamilnadu, India.

Mobile-9994338127, E-Mail: snc.nice@gmail.com

Access this Article online

Quick Response code

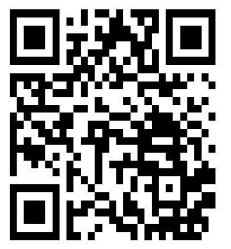

DOI: $10.16965 /$ ijar.2018.416

\section{R}

Revised: None
Journal Information

International Journal of Anatomy and Research ICV for 2016 ISSN (E) 2321-4287 | ISSN (P) 2321-8967

90.30 https://www.ijmhr.org/ijar.htm DOI-Prefix: https://dx.doi.org/10.16965/ijar

Article Information

Received: 29 Oct $2018 \quad$ Accepted: 14 Dec 2018

Published (O): 05 Jan 2019

Published (P): 05 Jan 2019

\section{INTRODUCTION}

Femur is the longest and strongest bone in the body.It's length is associated with a striding gait,it's strength with the weight and muscular forces which it must withstand [1]. It is about $45 \mathrm{~cm}$ long in an average adult man, that means, approximately one-fourth of the height of the individual. The bony trabeculae in the interior of the upper end of femur are arranged to withstand the weight of the body transmitted through the femoral head [2].

Anatomical study of femur bone serves helpful data to understand different aspect of clinical disease conditions including common site of fractures, changes in osteoporosis, associated congenital anomalies as well as medico legal cases. The neck of femur in humans is an important functional modification of femur after man took up his erect posture. The angle of inclination has been studied by many workers. The common implants used for the surgical treatment of proximal fracture namely screws and blades are designed primarily for use in western population, whose constitutional and 
biomechanic factors vary for the Indian population. According to Noble P.C [3] and Siwach [4] in Total Hip Arthroplasty, it is mandatory that design and dimensions of Femoral component match the anatomy of femur. Siwach has noted a gross geometrical difference between these western implants and Indian Femora.

\section{MATERIALS AND METHODS}

This study of femur was taken up at the Institute of Anatomy, Madurai Medical College with 60 Femora with age and sex no par. The following measurements were taken into consideration namely femur length, head circumference, anterior neck length, neck -shaft angle and intertrochanteric distance which were measured with the following instruments namely osteometric board, vernier caliper and goniometer. Measurements of femoral length, anterior neck length, neck - shaft angle(NSA) and head diameter were done according to standard anthropometric methods as shown in [Fig-1,2,3\&4]

Fig. 1: Measurement of length in osteometric board.

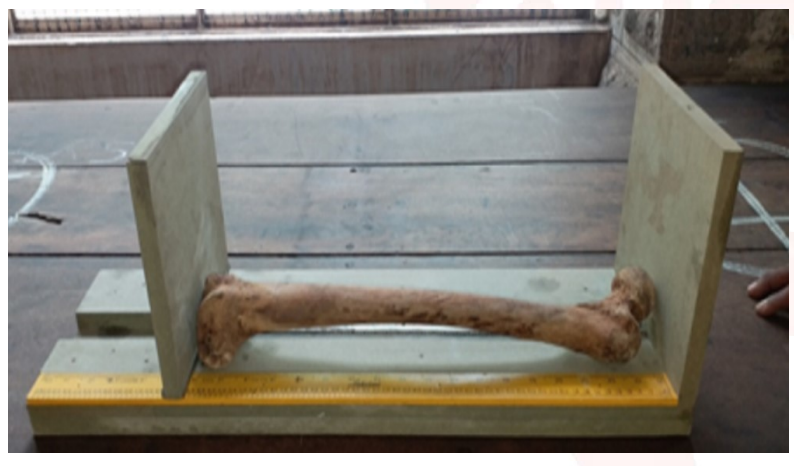

Fig. 2: Measurement of anterior neck length by vernier caliper.

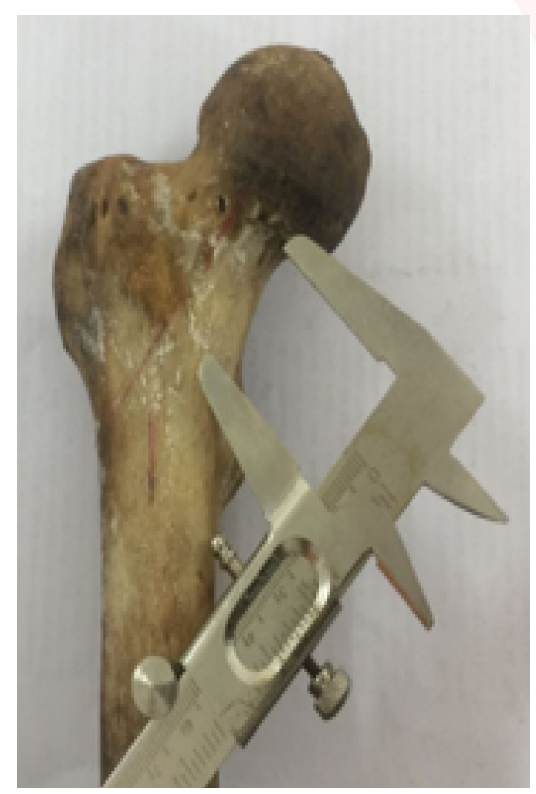

Fig. 3: Measurement of Neck -Shaft Angle with Goniometer.

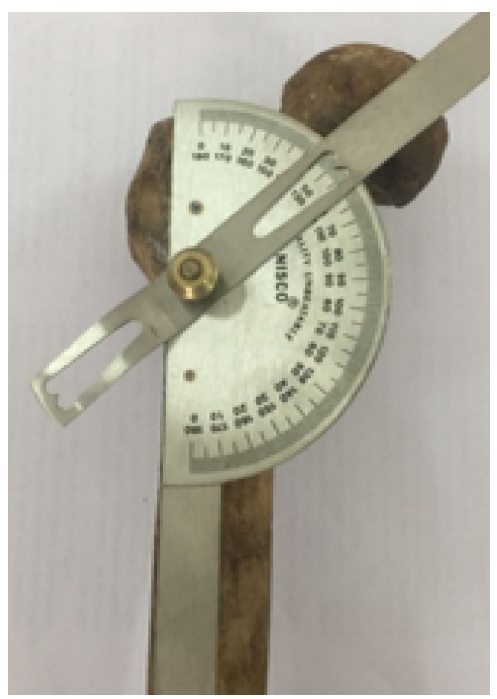

Fig. 4: Measurement of femoral head diameter.

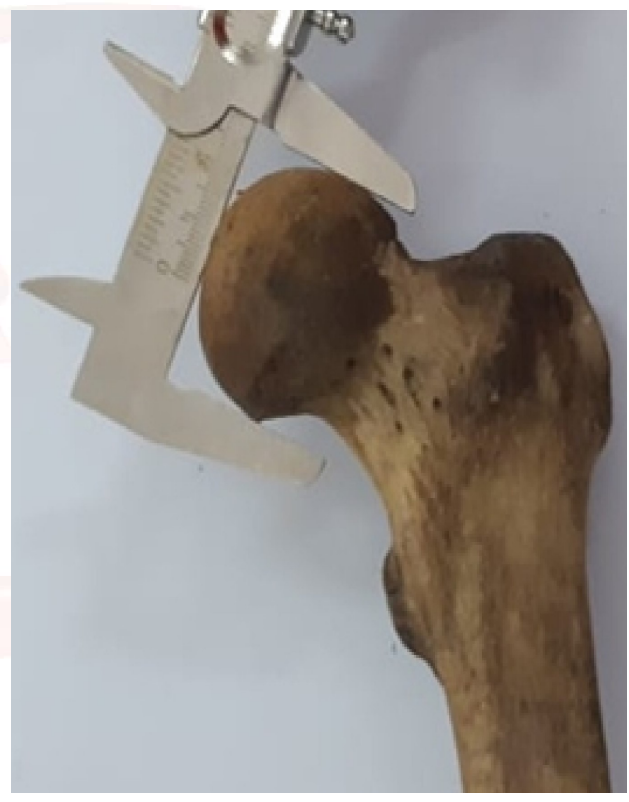

\section{RESULTS}

In this present study of proximal femora, the average femur length was $41.4 \mathrm{~cm}$, diameter of head was $4.17 \mathrm{~cm}$, anterior neck length $-3.42 \mathrm{~cm}$, , neck shaft angle $-129.9^{\circ}$ and the inter-trochanteric distance was $6.13 \mathrm{~cm}$. Age and sex were not taken into consideration in this study.

Table 1: Study of length of femur.

\begin{tabular}{|l|c|c|}
\hline \multicolumn{1}{|c|}{ Name of author } & Year & $\begin{array}{c}\text { Femur length } \\
\text { (In cm) }\end{array}$ \\
\hline Desouza et al [10] & 2010 & $\begin{array}{c}\text { R-42.6+/-6.1 } \\
\text { L-42+/-5.6 }\end{array}$ \\
\hline Shakil Mohammed et al [23] & 2014 & $44.6+/-2.6$ \\
\hline Ravi et al [17] & 2016 & $44.7+/-2.9$ \\
\hline Neelima et al [13] & 2016 & 41.5 \\
\hline Suja Robert et al [18] & 2017 & $41.9+/-3.4$ \\
Praba Nand Choudry et al [25] & 2017 & 41.3 \\
\hline Present study & 2018 & 41.4 \\
\hline
\end{tabular}


Table 2: Study of neck length compared by authors.

\begin{tabular}{|l|c|c|}
\hline \multicolumn{1}{|c|}{ Name of author } & Year & Neck length \\
\hline Ravichandran D et al [15] & 2011 & 30.09 \\
\hline Shakil Mohammed [23] & 2014 & $35.9 \mathrm{~mm}$ \\
\hline Subash Gujar et al [26] & 2013 & $\begin{array}{c}\text { L-34.20mm } \\
\text { R-34.50mm }\end{array}$ \\
\hline Mrunal Muley et al [14] & 2017 & $\begin{array}{l}\text { L-33.42mm } \\
\text { R-34.96mm } \\
\text { Praba Nand Choudry et al [25] }\end{array}$ \\
\hline Neelima et al [13] & 2017 & $28.8 \mathrm{~mm}$ \\
\hline Present study & 2016 & $27.5 \mathrm{~mm}$ \\
\hline
\end{tabular}

Table 3: Study of diameter of head of femur.

\begin{tabular}{|l|c|c|}
\hline \multicolumn{1}{|c|}{ Name of author } & Year & Diameter of head \\
\hline AK Mishra et al[16] & 2009 & $\begin{array}{c}42.9 \mathrm{~mm} \\
\mathrm{R}-31.1+/-2.7 \mathrm{~mm} \\
\mathrm{~L}-30.8+/-3 \mathrm{~mm}\end{array}$ \\
\hline D'souza et al [10] & 2010 & $12.5 \mathrm{~mm}$ \\
\hline Neelima et al [13] & 2016 & $41.7 \mathrm{~mm}$ \\
\hline Present study & 2018 & \\
\hline
\end{tabular}

Table 4: Study of neck shaft angle by various authors.

\begin{tabular}{|l|c|c|}
\hline \multicolumn{1}{|c|}{ Name of author } & Year & Neck shaft angle \\
\hline Siwach et al [4] & 2003 & $123.5^{\circ}$ \\
\hline Saikia et al [20] & 2008 & $139.5^{\circ}$ \\
\hline Ravichandran et al [15] & 2011 & $126.5^{\circ}$ \\
\hline Shakil mohammed et al [23] & 2014 & $137.1^{\circ}$ \\
\hline Ravi et al [17] & 2016 & $136.8^{\circ}$ \\
\hline Aparna gullapalli et al [24] & 2017 & $121^{\circ}$ \\
Praba nand choudry et al [25] & 2017 & $127.21^{\circ}$ \\
\hline Present study & 2018 & $129.9^{\circ}$ \\
\hline
\end{tabular}

\section{DISCUSSION}

Artificial Hip Replacement has become the latest trend in orthopaedics worldwide. As there are regional differences in the stature of human beings of specific population, the prosthesis to be designed should be very specific for successful surgical outcome. Implants for replacement of diseased hip joint were mostly made by European and American manufacturers according to the morphology of their own population. However, Indians are relatively small built and hence the local surgeons have very few choices of size available to them. If the implant is too large, the femur may fracture. So they tend to undersize to prevent fracture. But highly undersized bone may not align with the bone properly[5]. Reddy has also highlighted that a mismatch between femoral bone and stem may definitely result in micromotion which can lead to thigh pain, osteolysis and aseptic loosening.

The differences in anthropometry of the proximal femur between ethnicities due to disparity in lifestyle, physique etc., has been studied by different authors. Meenakshi Verma[6] has compiled them. A few excerpts from the compilation are as under.

Mahaisavariya[7] et al made a comparative study between Siamese and Caucasian populations and reported wider CDA (collodiaphyseal angle)for siamese.

Hoaglund \& Low[8] observed smaller femur neck width and CDA for Hongkong Chinese than their western counterpart.

Siwach and Dahiya[4] compared the parameters of Femur of Indian cadavers with those of western, Chinese and Hongkong population and found the data quite different from them.

Ho Jung Cho[9] et al showed the anatomic and geometric differences of femur in Korean subjects from American and Japanese and suggested to design new hip prosthesis system for Asian population.

De Sousa et al[10] studied Brazilian population with auto CAD 200 software and compared it with other studies of different regions and given their results on right and left respectively as femur length $-42.6+/-6.1 \& 42+/-5.6 \mathrm{~mm}$, neck length- 30.1+/-4.3 \& 30.5+/-4.1, head diameter$31.1+/-2.7 \& 30.8+/-3 \mathrm{~mm}$ of which though the first two parameters coincided with my study the head diameter was little less than my study.

There are several reported works where morphological data were used as reference for the design and analysis of femoral stem. These implants were specifically designed according to morphology of bone for accurate representation in an idealized situation. Gotze et al[11] proved the importance of a suitably matched implant for successful surgery through a custom made femoral stem, Adaptiva. Rawal $B R[12]$ et al have proposed dimension of the cementless femoral stem for Indian population. Neelima[13] has compared her study with the mean femoral length which was $414.83 \mathrm{~mm}$ with the measurement of seven other authors in her study. Study of femoral length by various authors is given in table $-1(10,23,17,13,18,25)$. The length of neck in her study was $27.5 \mathrm{~mm}$ and the diameter of head was $122.5 \mathrm{~mm}$ which was smaller compared to the present study showing that within our country there are regional 
differences among individuals.

Mrunal and Pritha[14] in their morphometric study of neck of adult femora has measured the neck length on anterior and posterior aspects as $34.96 \mathrm{~mm}$ and $33.42 \mathrm{~mm}$ respectively which was similar to the present study.

Mean neck length studied by Siwach[4] was $3.72 \mathrm{~cm}$ whereas Ravichandran[15] showed as $3.18 \mathrm{~cm}$ and compared their study with various authors given in Table- $2[15,23,26,14,25,13]$ and the anterior neck length in the present study was $3.42 \mathrm{~cm}$ which correlated with the above study and the head diameter was $41.7 \mathrm{~mm}$ which correlated with other study shown in Table$3[16,10,13]$. Mishra's[16] study on femoral head diameter in Nepalese was $44.26 \mathrm{~mm}$ which was higher than the present study implicating the variations among Asians too. He compared his value with western population who had an average of $46.1 \mathrm{~mm}$ which is greater than Asians stressing up the need for designing of implants with our own morphometry.

Ravi[17] in his study has given femoral length 447.1+/-28.94, neck length - 36.3+/-5.4mm, neck shaft angle as $136.8^{\circ}$ and concluded that there is no significance between right and left femur measurements.

Suja Robert[18] in her morphometric study has shown femur length as $41.9+/-3.4 \mathrm{~cm}$ and intertrochanteric distance as $5.81 \mathrm{~cm}$. The inter-trochanteric distance in the present study was 6.13 $\mathrm{cm}$. which correlated with the above study.

Prasth RA and Ismail BM[19] observed that femoral head diameter in south Indian population was $41.98+/-1.98 \mathrm{~mm}$, femoral length409.4 $(R), 416.9(L)$, anterior neck length of $28.8 \mathrm{~mm}(B)$, NSA of $126.78(R), 127.64(L)$ correlating with the present study.

Saikia $\mathrm{KC}[20]$ has observed variations of NSA between North East population and Caucasians. Several authors have performed study of NSA which are shown in Table-4[4,20,15,23, $17,24,25]$.In this study the average neck shaft angle was $129.9^{\circ}$. All the above studies which were done with the Indian femora show similar results as the present study. Baharuddin[21] in his study of Malay people has given femoral head diameter in males \& females as 43.62 \& $38.85 \mathrm{~mm}$ respectively which is very closer to the values in the present study, but the neck length was high which was $91.08 \& 81.78 \mathrm{~mm}$. Various population based studies of proximal femora have concluded that there was gross difference in anthropometry between Asians and other western population,

Reddy et al [5] has concluded in their study that in case of Total Hip Replacement surgeries anterior thigh pain, aseptic loosening, intraoperative splintering and fractures are common complications because of oversized femoral components particularly in uncemented varieties. Implant morphological mismatch that might cause difficulties during implant placement and further complications were studied by Chauhan et al[22] who concluded that the variations in the parameters of the proximal femur and acetabulum were insignificant among different population in India but the data of two different countries varied significantly. Thus it is clear that the proximal femoral geometry varies among different ethnic groups, Therefore usage of implants designed exclusively for western bone will not suit the other ethnic groups.

Mishra et al[16] in their study on a second look at rational of implant design for the proximal femur have concluded that the western implants should be used only after careful consideration in Indians. He also stresses that the fracture implant designs should be specific for Indian bones.

\section{CONCLUSION}

This study indisputably shows that the dimensions of Indian femora are lesser than the western population which will not get on with the implants available in the commercial market which will lead to snags ultimately landing the orthopaedic surgeons in trouble irrespective of their skills. In this present study of proximal femora, the average femur length was $41.4 \mathrm{~cm}$, diameter of head was $4.17 \mathrm{~cm}$, anterior neck length being $3.42 \mathrm{~cm}$, neck shaft angle was $129.9^{\circ}$, and the inter-trochanteric distance being $6.13 \mathrm{~cm}$. Age and sex were not taken into consideration in this study.

\section{Conflicts of Interests: None}

\section{REFERENCES}

[1]. Standring S(ed)In. NeilR Borley,Patricia Collins, Alen R Crossman(editors).Gray's Textbook of Anatomi- 
cal basis ofclinical practice; $40^{\text {th }}$ edition;Elsevier Churchill Livingstone,Spain.2008;434.

[2]. A.K.Dutta. Essentials of Human Osteology.current books international,july 2005.

[3]. Noble PC, Alexander JW, LindahI L, Yew DT, Granberry WM, Tullos HS. The anatomic basis of femoral component design.Clin Orthop Relat Res., 1988;235:14865.

[4]. Siwach RC, Dahiya S. Anthropometric study of proximal femur geometry and its clinical application.Indian Journal of Orthopaedics 2003;37(40):247-251.

[5]. Reddy V, Moorthy G, Reddy S, Krishna M, Gopikrishna K. Do we need a special design of femoral component of total hip prosthesis in our patient?Indian J.Orthop., 1999;33(4):282-4.

[6]. Meenakshi Verma et al. Morphometry of proximal femur in Indian population.Journal of clinical and diagnostic research.2017;11(2):ACO1-ACO4.

[7]. Mahaisavariya B, Sitthiseripratip K, Tongdee T, Bohez E.L, Vander Sloten J, Oris P. Morphological study of the proximal Femur:a new method of geometrical assessment using 3-dimensional reverse engineering.Med Eng Phys., 2002;24(9):617-22.

[8]. Hoagland F.T \&Low W.D.Anatomy of the femoral neck and head, with comparative data from Caucasians and Hongkong Chinese.Clin.Orthop. Relat.Res., 1980;152:10-16.

[9]. Ho Jung Cho, Dai-Soon Kwak, In Beom Kim. Morphometric evaluation of Korean femurs by geometric computation:Comparisons of the sex and the population;Biomed Research I,vol2 Article ID 730538,9pg

[10]. De SousaE, Fernandes R.M.P, Mthias m.b, Rodrigues M.R, Abram a.j, Babinski m.a. Morphometric Study of the Proximal Femur Extremity in Brazilians. Int J. Morphol.,2010;28(3):835-40.

[11]. Gotze C, Steens W, Vieth V, Poremba C, Claes I \& Steinbeck J. Primary Stability in cementless femoral stem:Custom made versus conventional femoral prosthesis.Clin.Biomech., 2002;17(4):267-73.

[12]. BR Rawal, Rahul Ribeiro, Rajesh Malhotra,Naresh Bhatnagar. Anthropometric measurements to design best fit femoral stem for the Indian population. Indian J Orthop.2012;46(1):46-53ss.
[13]. Neelima P,Ravisundar r,Hima Bindu A.A Study on Morphometric measurements of adult dried femora in vishakapatnam.Int J Adv Res 2016;4(8),564-567.

[14]. Mrunal Muley, Pritha Bhuiyan. Morphometric study of neck of adult femora. International Journal of Anatomy and Research 2017;5 (3):4317 -20.

[15]., Ravichandran D et al. Proximal femoral geometry in Indians and its clinical applications.J Anat Soc.India 2011;60(1):6-12.

[16]. Mishra AK, Chalise P, SinghRP, Shah RK. The proximal femur a second look at rational of implant design. Nepal Med COLL J 2009;11(4):278-280

[17]. Ravi et al. A Morphological study of Femur and its clinical importance. Int J Intg Med Sci 2016;3(7):34144.

[18]. Suja Robert Sarasammal et al.Correlation of length of femur with its proximal fragments-A Morphometric study.JEMDS 2017;6(70):4975-4978.

[19]. Prasth RA,Ismail BM.Acorrelative study of morphometric analysis of acetabulum and femral head in male and female south Indian human cadavers.Journal of science 2014;4(1)4-8.

[20]. Saikia KC,Bhuyan SK,Rongphar R.Anthropometric study of the hip joint in Northeastern region population with computed tomography scan.Indian J Orthop 2008;42:260-6.

[21]. Mohd Yusof Baharuddin et al,Morphology study of the proximal Femur in Malay population.Int J Morphol 2015;29(4):1321-1325.

[22]. Chauhan R, Paul S, Dhon BK .Anatomical parameters of North Indian Hip Jonts:Cadaveric Study.J Anat Soc India 2002;51:39-42

[23]. Shakil Mohammed khan,Shaik Hussain Saheb.Int J anat Res 2014;2(40):633-35.

[24]. Aparna Gullapali,Anil Kumar Inuganti. Morphometric study of Femoral Neck shaft angle and its clinical significance.Int J Anat Res 2017;5(3.2):4261-64.

[25]. Praba Nand Chaudhary,VS Shirol,Rajendra D Virupaxi.A Morphometric study of femoral length,anterior neck length, and neck-shaft angle in dry femora:A cross-sectional study.Indian J Health Sci Biomed Res 2017;10:331-334.

[26]. Subash Gujar, Sanjay Vikani, Jigna Parmar, KV Bondre. A correlation between femoral neck shaft angle to femoral neck length.IJBAR;2013:295-7.

How to cite this article:

Sobana M, Nedunchezhiyan S. OSTEOMETRIC STUDY OF PROXIMAL FEMUR. Int J Anat Res 2019;7(1.1):6108-6112. DOI: 10.16965/ijar.2018.416 